\title{
Pre-exposure prophylaxis in a new era of HIV prevention
}

Carlos Muzlera, Nicole Arseneau

Faculty Reviewer: Bill Thompson, MD, FRCPC (Department of Internal Medicine, Division of Infectious Diseases)

\section{CASE INTRODUCTION: LINDA}

Linda is a healthy, 25-year-old married woman living in the city of Toronto who presents with questions about human immunodeficiency virus (HIV) prevention. Linda and her husband met on an online dating forum in 2011 and married each other one year later while they were both seronegative. She describes her and her husband as having an "open" marriage and have had 2 and 5 extramarital partners, respectively. In 2014, Linda's husband was incidentally diagnosed with HIV infection after donating blood at a clinic, and Linda received testing shortly thereafter which came back negative for HIV. His viral load had reached 20000 copies/mL and he immediately began highly active antiretroviral therapy (HAART). His infection has stabilized with undetectable viral loads and a CD4 ${ }^{+}$ T-helper cell count of 1000 cells $/ \mu \mathrm{L}$; however, the risk of transmission has created damaging tensions within their marriage. Prior to his diagnosis Linda reports condom usage of less than $50 \%$ for both herself and her husband; however, the anxiety and fear of infection has prompted usage of over $90 \%$. Linda wants to be at ease in her sexual endeavours but is motivated to remain uninfected so she can be healthy to take care of her husband. She read about a new drug on Twitter that can prevent HIV infection in non-infected people and requests your counsel on it. She has an unremarkable history with respect to sexually transmitted infections (STIs), drug use, smoking and hepatitis, and has had no recent symptoms of fever, malaise, or sore throat.

\section{HIV AND SCREENING}

$\mathrm{HIV}$ is a blood-borne, sexually-transmissible retrovirus that targets the immune system by depleting $\mathrm{CD} 4^{+} \mathrm{T}$-helper cells, inverting the CD4/CD8 T-cell ratio, and enabling susceptibility of the host to opportunistic infections. ${ }^{1,2}$ The progression of HIV infection can be divided into 3 stages beginning with an acute retroviral syndrome in the first 2 weeks post-infection, followed by a clinically latent, asymptomatic phase, and finally a severely immunocompromised phase termed acquired immune deficiency syndrome (AIDS), characterized by opportunistic infection and significant mortality.,

Transmission of HIV occurs from contact between specific body fluids of infected individuals and vulnerable surfaces of HIV-negative persons, namely mucosal membranes including the lining of the mouth, anus, reproductive system, and urogenital tract. ${ }^{3,4}$ Persons at high risk therefore include injection drug users and their sex partners, persons who exchange sex for money or drugs, sex partners of HIV-infected persons, men who have sex with men (MSM), and persons who have unprotected sex and a large number of sexual partners. ${ }^{4}$ Linda's history of a long-term HIV-positive primary sexual partner and non-monogamy therefore elevates her risk of infection. It would also be prudent to take a detailed medical history for any signs of acute retroviral syndrome (fever, headache, malaise, sore throat, lymphadenopathy, and skin rash) or HIV wasting syndrome (chronic diarrhea and weight loss with unidentified cause) as this will inform her clinical staging, urgency of HIV testing, and the type of test required. ${ }^{2,4}$ This initial consultation provides an opportunity for her physician to advise of the importance of periodic testing and offer prevention counseling.

\section{PHARMACOLOGICAL PREVENTION}

The Public Health Agency of Canada has estimated a prevalence of over $75000 \mathrm{HIV}$-positive individuals living in Canada, with an incidence plateauing at just over 2000 new cases per year. ${ }^{5}$ An estimated $25 \%$ of these individuals are unaware of their HIV status, and this number climbs to $33 \%$ in Ontario. ${ }^{5}$ Given the need for additional strategies to further prevent HIV infection, particularly amongst high risk populations, Health Canada recently gave Gilead Sciences Canada approval for the use of Truvada ${ }^{\circledR}$ (TDF-FTC) as Pre-exposure Prophylaxis (PrEP) in February 2016. ${ }^{6}$ PrEP is a fixed dose combination of tenofovir disoproxil fumarate $(300 \mathrm{mg})$ and emticitabine (200 mg, TDF-FTC), both of which are nucleoside reverse transcriptase inhibitors that prevent viral replication by interrupting HIV-DNA synthesis. ${ }^{7}$ PrEP has shown dramatic protective effects in HIV-negative high risk groups including nonmonogamous MSM, HIV-discordant couples and injection drug users. $^{8-13}$ The results of clinical trials for serodiscordant heterosexual couples are summarized in Table 1 as they pertain to Linda's scenario. These studies reveal the critical contribution of adherence to the preventive outcomes of PrEP against HIV infection. The relative risk reduction conferred by PrEP in the Partners PrEP study increased to $90 \%$ when the authors performed a subgroup analysis on individuals with detectable drug levels..$^{10}$ Furthermore, both the FEM-PrEP and VOICE trials were unable to demonstrate clinical efficacy of PrEP largely due to non-adherence rates that far exceeded $50 \%$ of participants in both trials. ${ }^{12,13}$ Notably, it was found that drug-resistant strains were most prevalent amongst seroconverters who were acutely infected with HIV at baseline or suboptimally adhered to treatment. ${ }^{12,13}$ Thus the importance of screening Linda for $\mathrm{HIV}$ infection before initiating PrEP and monitoring her adherence cannot be overstated.

Linda's physician collects a blood sample to be sent for a 4th Generation Enzyme Immunoassay test, which detects the presence of both protein p24 antigen (viral core protein) and HIV antibodies. Linda reveals in her sexual history that she was last sexually active with her husband without a condom over 4 months ago, with only a handful of protected sexual encounters since that time, and none whatsoever with extramarital partners. When she returns for follow-up 2 weeks later, she receives good news that the test results were negative, ruling out a diagnosis of HIV at this time. 


\section{CLINICAL INDICATION}

A brief risk assessment by Linda's physician should bring to light her inconsistent use of condoms, her extra-marital sexual partners, and HIV-positive primary sexual partner. Granted her husband is adherent to HAART therapy, a recent clinical trial (HPTN 052) suggests this is highly protective (96\% risk reduction) against HIV transmission to a heterosexual partner. ${ }^{14}$ Nevertheless, the same trial conveyed that a quarter of patients who seroconverted were infected by external partners, obviating the fact that Linda's extra-marital encounters elevate her risk for infection. This becomes unsurprising when taking into account the low rates of consistent condom use and the fact that nearly a quarter of HIV-positive Canadians are undiagnosed. ${ }^{5}$ Furthermore, if her husband's HIV infection is not monitored, her risk of infection becomes 8 times that of women with partners of unknown status according to a recent cohort study (HPTN 064) ${ }^{15}$ Linda's clinician must therefore feel comfortable asking about factors that influence the appropriateness of PrEP. This includes asking about risky sexual behaviours and the use of substances that could influence these behaviours, hepatic or renal health, or medication adherence. According to the Center for Disease Control and Prevention, PrEP is clinically indicated in heterosexual men and women who are at high risk of HIV infection, which includes those having an HIV-positive sexual partner and a history of inconsistent condom use, both of which have been identified in Linda's history. ${ }^{16}$

\section{INFORMED DECISION MAKING}

PrEP conveys both challenges and opportunities that Linda's physician should aid in elucidating and aligning with her wishes and values. There is an increasing concern that the seemingly flawless protection incurred by PrEP will prompt individuals to participate in riskier sexual behaviour that may blunt its protective effects. ${ }^{17}$ Several studies have explored sexual risk compensation when individuals use oral PrEP and have found no clinically significant change in the frequency of sexually risky behaviours or STIs. ${ }^{18-20}$ Furthermore, this concern is founded on the assumption that condom use is highly prevalent within serodiscordant couples and therefore a significant reduction would have substantial impact. The evidence, although limited, suggests that condom use is not common, with only $10 \%$ to $30 \%$ of serodiscordant couples in the United States (US) reporting consistent condom use. ${ }^{21}$ That being said, the level of protection imparted by proper, consistent condom use is comparable ( $85 \%$ to $95 \%$ risk reduction) to that of PrEP. Considering patients may often become non-adherent or unable to afford PrEP, and that PrEP doesn't protect against other STIs, condoms are a necessary component of any comprehensive HIV prevention toolkit. ${ }^{22,23}$ PrEP also comes with an annual cost of $\$ 12000$ USD to $\$ 15000$ USD that patients must pay out of pocket or through private insurance while provincial policy makers negotiate the terms for coverage of PrEP. ${ }^{6,24}$ To that end, patients must consider if the cost of PrEP and its associated side effects are worth absorbing.

Table 1. Summary of clinical trials of TDF/FTC (PrEP) in heterosexual men and women

\begin{tabular}{|c|c|c|c|c|c|c|c|}
\hline \multirow{2}{*}{ Study } & \multirow{2}{*}{$\begin{array}{c}\text { Design - Evidence } \\
\text { Quality }\end{array}$} & \multicolumn{2}{|c|}{ Participants } & \multirow{2}{*}{\multicolumn{2}{|c|}{$\begin{array}{r}\text { Effect - HR [Efficacy } \\
\text { Estimate] }(95 \% \mathrm{Cl})\end{array}$}} & & \multirow{2}{*}{ Limitations } \\
\hline & & Agent & Control & & & & \\
\hline \multirow{4}{*}{$\begin{array}{l}\text { Partners PrEP } \\
\text { (heterosexual men and } \\
\text { women) }\end{array}$} & \multirow{4}{*}{ Phase 3 - High } & \multirow{4}{*}{$\begin{array}{l}\text { 1. TDF } \\
(n=1589) \\
\text { 2. TDF/FTC } \\
(n=1583)\end{array}$} & \multirow{4}{*}{$\begin{array}{l}\text { Placebo } \\
(n=1586)\end{array}$} & & TDF & TDF/FTC & \multirow{4}{*}{ Minimal } \\
\hline & & & & All & $\begin{array}{l}0.33[67 \%] \\
(0.19-0.56)\end{array}$ & $\begin{array}{l}0.25[75 \%] \\
(0.13-0.45)\end{array}$ & \\
\hline & & & & Women & $\begin{array}{l}0.29[71 \%] \\
(0.13-0.63)\end{array}$ & $\begin{array}{l}0.34[66 \%] \\
(0.16-0.72)\end{array}$ & \\
\hline & & & & Men & $\begin{array}{l}0.37[63 \%] \\
(0.17-0.80)\end{array}$ & $\begin{array}{l}0.16[84 \%] \\
(0.06-0.46)\end{array}$ & \\
\hline $\begin{array}{l}\text { TDF2 (heterosexual men } \\
\text { and women) }\end{array}$ & Phase 2 - Moderate & $\begin{array}{l}\text { TDF/FTC } \\
(n=611)\end{array}$ & $\begin{array}{l}\text { Placebo } \\
(n=608)\end{array}$ & $\begin{array}{l}0.38[62 \%] \\
(0.17-0.79)\end{array}$ & & & $\begin{array}{l}\text { High loss to follow-up, } \\
\text { modest sample size }\end{array}$ \\
\hline $\begin{array}{l}\text { FEM-PrEP (heterosexual } \\
\text { women) }\end{array}$ & Phase 3 - Low & $\begin{array}{l}\text { TDF/FTC } \\
(n=1062)\end{array}$ & $\begin{array}{l}\text { Placebo } \\
(n=1058)\end{array}$ & $\begin{array}{l}0.94[6 \%]^{c} \\
(0.59-1.52)\end{array}$ & & & $\begin{array}{l}\text { Stopped at interim } \\
\text { analysis, limited } \\
\text { follow-up time and very } \\
\text { low adherence to } \\
\text { treatment protocol }\end{array}$ \\
\hline \multirow[b]{2}{*}{$\begin{array}{l}\text { VOICE (heterosexual } \\
\text { women) }\end{array}$} & \multirow[b]{2}{*}{ Phase 2B - Low } & \multirow{2}{*}{$\begin{array}{l}\text { 1. TDF } \\
(n=1007) \\
\text { 2. TDF/FTC } \\
(n=1003)\end{array}$} & \multirow[b]{2}{*}{$\begin{array}{l}\text { Placebo } \\
(n=1009)\end{array}$} & TDF & \multicolumn{2}{|c|}{ TDF/FTC } & TDF arm stopped at \\
\hline & & & & $\begin{array}{l}1.49[-50 \%]^{c} \\
(0.97-2.3)\end{array}$ & $\begin{array}{l}1.0 \\
(0\end{array}$ & $\begin{array}{l}4 \%]^{c} \\
-1.5)\end{array}$ & $\begin{array}{l}\text { interim analysis, very } \\
\text { low adherence to } \\
\text { treatment protocol in } \\
\text { both arms }\end{array}$ \\
\hline
\end{tabular}

${ }^{a}$ All trials in this table are randomized, controlled, double-blind, prospective clinical trials

b GRADE quality ratings:

High = further research is very unlikely to change our confidence in the estimate of effect

Moderate $=$ further research is likely to have an important impact on our confidence in the estimate of effect and may change the estimate

Low $=$ further research is very likely to have an important impact on our confidence in the estimate of effect and is likely to change the estimate

Very low = any estimate of effect is very uncertain

${ }^{c}$ Not statistically significant 
Additional bloodwork for hepatitis $B$ virus ( $H B V)$ serology and renal function measurements showed positivity for hepatitis $B$ surface antibody and an estimated creatinine clearance $(\mathrm{eCrCl})$ of 104 $\mathrm{mL} / \mathrm{min}$. This suggests the presence HBV immunity and normal renal function. After a discussion about risk-reducing practices, benefits, side effects, and costs of PrEP, and the importance of adherence to the medication, Linda was prescribed oral PrEP (Truvada ${ }^{\circledR}$ ) to be taken once per day regardless of sexual activities for 90 days with renewal only after repeat HIV testing.

\section{CLINICAL MONITORING AND COUNSELING}

Once PrEP has been initiated, patients are recommended for initial follow-up after 1 month for side effect monitoring and every 3 months thereafter for repeat HIV testing, pregnancy testing, assessing side effects and signs of acute infection, adherence, HIV acquisition risk behaviours, and for reinforcing risk-reducing behaviours. ${ }^{16}$ The physician should also monitor eCrCl every 6 months to ensure it remains $\geq 60 \mathrm{~mL} / \mathrm{min}$ and re-evaluate the need to continue PrEP if their patient's risk category has changed. ${ }^{16} \mathrm{HIV}$ treatment regimens containing TDF have documented decreases in renal function leading to occasional cases of acute renal failure. ${ }^{16,17,24}$ It is also necessary to test for HBV infection prior to initiating therapy as TDF and FTC have known activity against HBV and should an infected patient discontinue PrEP, their liver function needs to be closely monitored. ${ }^{16}$

Linda's success will largely depend on the adherence of her and her husband to their treatment regimens and willingness to address their risk factors. Side effects are a common cause of non-adherence and clinicians are responsible for informing patients and developing a plan for managing adverse effects. Fortunately for Linda, PrEP has proven to be very well-tolerated and although she currently is in a high exposure risk category, the success garnered from PrEP can promote positive reinforcing behaviors. ${ }^{25}$ Couples have felt PrEP helped them cope with their serodiscordance and met their fertility needs. ${ }^{25}$ Remaining HIV-negative during regular checkups also yielded motivation to continue adherence to PrEP and instilled confidence in the advice of their physician and ancillary services. ${ }^{25}$

At her follow-up Linda expresses her gratitude as PrEP has diminished the fear of transmission in her marriage and tremendously improved her sex life. She reports being compliant with the treatment regimen and has only experienced mild headache and nausea that has since resolved itself. She recently found full-time employment as a hospital pharmacist, which will provide sufficient funds to maintain her prescription until provincial coverage is offered.

\section{REFERENCES}

1. Simon V, Ho DD, Karim QA. HIV/AIDS epidemiology, pathogenesis, prevention, and treatment. Lancet. 2010;368(9534):489-504.

2. Maartens G, Celum C, Lewin SR. HIV infection: epidemiology, pathogenesis, treatment, and prevention. Lancet. 2014;384(9939):258-71.

3. Zuckerman RA, Whittington WLH, Celum CL, et al. Higher Concentration of HIV RNA in Rectal Mucosa Secretions than in Blood and Seminal Plasma, among Men Who Have Sex with Men, Independent of Antiretroviral Therapy. J Infect Dis. 2004;190(1):156-61.
4. Canadian AIDS Society [Internet]. Ottawa (ON): Canadian AIDS Society; c2013. HIV Transmission Guidelines for Assessing Risk; c2013 [cited 2016 March 5]. Available from: http://www.cdnaids.ca/hivtransmissionguidelinesforassessi

5. Summary: Estimates of HIV incidence, prevalence and proportion undiagnosed in Canada, 2014 [Internet]. Ottawa (ON): Public Health Agency of Canada; 2015 [cited 2015 March 5]. Available from: http:// healthycanadians.gc.ca/publications/diseases-conditions-maladies-affections/hiv-aids-estimates-2014-vih-sida-estimations/index-eng.php

6. Global News [Internet]. Toronto (ON): Shaw Media; 2016. Doctors celebrate as Health Canada approves Truvada as HIV-prevention therapy; 2016 [cited 2016 March 5]. Available from: http://globalnews. ca/news/2547824/doctors-celebrate-as-health-canada-approves-truvada-as-hiv-prevention-therapy/

7. Naswa S, Marfatia YS. Pre-exposure prophylaxis of HIV. Indian J Sex Transm Dis. 2011;32(1):1-8.

8. Grant RM, Lama JR, Anderson PL, et al. Preexposure Chemoprophylaxis for HIV Prevention in Men Who Have Sex with Men. N Engl J Med. 2010;363(27):2587-99.

9. Molina JM, Capitant C, Spire B, et al. On-Demand Preexposure Prophylaxis in Men at High Risk for HIV-1 Infection. N Engl J Med. 2015;373(23):2237-46.

10. Baeten JM, Donnell D, Ndase P, et al. Antiretroviral Prophylaxis for HIV Prevention in Heterosexual Men and Women. N Engl J Med. 2012;367(5):399-410.

11. Thigpen MC, Kebaabetswe PM, Paxton LA, et al. Antiretroviral Preexposure Prophylaxis for Heterosexual HIV Transmission in Botswana. N Engl J Med. 2012;367(5):423-34.

12. Van Damme L, Corneli A, Ahmed K, et al. Preexposure Prophylaxis for HIV Infection among African Women. N Engl J Med. 2012;367(5):41122.

13. Marrazzo JM, Ramjee G, Richardson BA, et al. Tenofovir-based Preexposure Prophylaxis for HIV Infection among African women. N Engl J Med. 2015;372(6):509-18.

14. Cohen MS, Chen YQ, McCauley M, et al. Prevention of HIV-1 Infection with Early Antiretroviral Therapy. N Engl J Med. 2011;365(6):493-505.

15. Eshleman SH, Hughes JP, Laeyendecker O, et al. Use of a Multifaceted Approach to Analyze HIV Incidence in a Cohort Study of Women in the United States: HIV Prevention Trials Network 064 Study. J Infect Dis. 2013;207(2):223-31.

16. US Public Health Service. Preexposure Prophylaxis for the Prevention of HIV Infection in the United States - 2014: A Clinical Practice Guideline. 2014.

17. McMahon JM, Myers JE, Kurth AE, et al. Oral Pre-Exposure Prophylaxis (PrEP) for Prevention of HIV in Serodiscordant Heterosexual Couples in the United States: Opportunities and Challenges. AIDS Patient Care and STDs. 2014;28(9):462-74.

18. Mugwanya KK, Donnell D, Celum C, et al. Sexual Behaviour of Heterosexual Men and Women Receiving Antiretroviral Pre-Exposure Prophylaxis for HIV Prevention: A Longitudinal Analysis. Lancet Infect Dis. 2013;13(12):1021-28.

19. Guest G, Shattuck D, Johnson L, et al. Changes in sexual risk behavior among participants in a PrEP HIV prevention trial. Sex Transm Dis. 2008;35(12):1002-8.

20. Marcus JL, Glidden DV, Mayer KH, et al. No Evidence of Sexual Risk Compensation in the iPrEx Trial of Daily Oral HIV Preexposure Prophylaxis. PLoS One. 2013;8(12).

21. van der Straten A, Gómez CA, Saul J, et al. Sexual risk behaviors among heterosexual HIV serodiscordant couples in the era of 
post-exposure prevention and viral suppressive therapy. AIDS.

2000;14(4):F47-54.

22. Centers for Disease Control and Prevention. Recommendations for HIV Prevention with Adults and Adolescents with HIV in the United States, 2014. 2014.

23. Weller S, Davis-Beaty K. Condom effectiveness in reducing heterosexual HIV transmission. Cochrane Database of Systematic Reviews. 2002;1:1-25.

24. Bridget H. Considering Pre-Exposure Prophylaxis: Do the Pros Outweigh the Cons as an HIV Prevention Strategy? LGBT Health. 2014;1(4):253-5.

25. Ngure K, Heffron R, Curran K, et al. I Knew I Would Be Safer. Experiences of Kenyan HIV Serodiscordant Couples Soon After Pre-Exposure Prophylaxis (PrEP) Initiation. AIDS Patient Care STDs. 2016;30(2):78-83. 